\title{
ANTIMICROBIAL ACTIVITY AND IN SILICO STUDY OF METHYLIMIDAZOLIUM-FURANCHALCONE HYBRIDS AND 1-ALKYL-3-METHYLIMIDAZOLIUM SALTS
}

\author{
PEDRONEL ARAQUE ${ }^{b, *}$, ANGIE HERRERA ${ }^{a}$, DIEGO MONTAÑO ${ }^{c}$, ANDRES YEPES $^{a}$, \\ ELISA GARCÍA ${ }^{a}$, JOVANY SEPÚLVEDA ${ }^{c}$, SANDRA TORIJANO ${ }^{b}$ AND WILSON CARDONA-G ${ }^{a, *}$

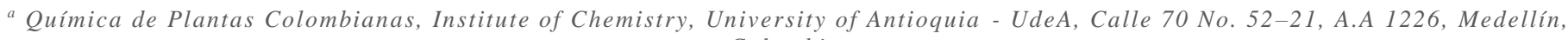 \\ Colombia. \\ ${ }^{b}$ Grupo de Investigación e Innovación en Formulaciones Químicas, University EIA, km $2+200$ Vía \\ José María Córdova airport, Postal Code 055428, Envigado, Colombia. \\ c Corporación Universitaria Americana, Sede Medellín, Cra. 42 No. 52 - 06, Av. La Playa, Colombia.
}

\begin{abstract}
A set of methylimidazolium-furanchalcone hybrids and 1-alkyl-3-methylimidazolium salts were tested in order to find their antimicrobial activity against five gram positive bacteria, two gram negative bacteria and three fungi. In the series of 1-alkyl-3-methylimidazolium salts, compounds $\mathbf{4}$ and $\mathbf{7}$ were the most active compounds against $S$. mutans and F. oxysporum, respectively (MIC value of 3.0 and $6.7 \mathrm{mM}$, respectively). In addition, among the hybrid molecules, compound $\mathbf{1 0}$ exhibited the highest activity against $F$. solani $\left(\mathrm{MIC}_{50}=14.3 \mathrm{mM}\right)$ followed by hybrid $\mathbf{1 1}\left(\mathrm{MIC}_{50}=14.5 \mathrm{mM}\right)$, which was also the most active against $S$. aureus, $S$. mutans $\left(\mathrm{MIC}_{50}\right.$ $=14.6,18.7 \mathrm{mM}$, respectively). The activity of these hybrids was even better with regard to the lead compounds (furanchalcone, methylimidazole or the mixture). In the structure-activity relationship there was observed higher bioactivity when the alkyl linker had eigth carbon atoms. This was then supported by the in silico study which displayed a strong relationship between the length of the alkyl chain on $\mathrm{N}$ and the biological activity. The results highlight the importance of these derivatives (1-alkyl-3-methylimidazolium salts) and hybrids (methylimidazolium-furanchalcone) as potential antimicrobial agents.
\end{abstract}

Keywords: Antibacterial, antifungal, ionic liquid, in silico study, hybrid molecules.

\section{INTRODUCTION}

The rise in antimicrobial resistance to conventional treatments is rapidly increasing, and therewith, increase the failed efforts to develop novel classes of antibiotics ${ }^{1-3}$. Thus, infections caused by multi resistant bacteria and fungi are one of the fastest growing medical threats to modern society ${ }^{4}$. Available antimicrobial compounds are limited and, due to the restricted spectrum of action, toxicity, extensive side effects and drug interactions, the scientific community is forced to search new therapeutic alternatives ${ }^{5-8}$. Due to the above, it is vital to discover novel scaffold for the design of new antimicrobial agents in order to help in the fight against these pathogenic microorganisms.

In this matter, the imidazole nucleus is presented in a significant number of biomolecules and the inclusion of this moiety in organic scaffolds is considered an important synthetic strategy in drug discovery ${ }^{9-10}$. In the last decades, the wide pharmacological potential of the imidazole and imidazolium derivatives was well demonstrated by the increasing number of the reported bioactivities ${ }^{11-15}$ including antimicrobial activity ${ }^{16-21}$, which is closely related to their surfactant properties $^{22,23}$.<smiles>O=C(/C=C/c1ccco1)c1ccc(O)cc1</smiles>

Furanchalcone<smiles>Cn1ccnc1</smiles>

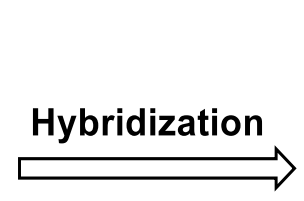<smiles>[BH3-]</smiles><smiles>C1CCCCC1</smiles>

\author{
3-methylimidazolium-Furanchalcone hybrids
}

Besides, recent toxicology data indicate a strong correlation between the length of the alkyl chain appended to the imidazolium derivatives cation and the resulting toxicity ${ }^{24-26}$. On the other hand, chalcones represent an essential group of natural or synthetic products, some of them with a wide range of pharmacological activities ${ }^{27}$. Furthermore, heterocyclic chalcones have been reported due to the wide range of biological properties, especially antibacterial ${ }^{28-30}$ and antifungal activitiy ${ }^{31}$.

In recent years, it has emerged a promising strategy based on hybrid molecules which bear in their structures two distinct pharmacophores and thus can exhibit a dual mode of action, however, do not necessarily act on the same biological target ${ }^{32-36}$.

In this work, a series of methylimidazolium-furanchalcone hybrids (Figure 1) were evaluated in order to find the effect of the hybridazation and the alkyl chain attached to the head polar group in the antimicrobial activity when these compounds were compared with 1-alkyl-3-methylimidazolium derivatives.

\section{3-methylimidazole}<smiles>BrCC(Br)CBr</smiles>

\section{Linker}

Figure 1. Design of 3-methylimidazolium-furanchalcone hybrids as antimicrobial agents. 


\section{EXPERIMENTAL}

\subsection{Materials and methods}

PDA (Potato Dextrose Agar, Oxoid), Nutrient agar (Scharlau Microbiology 01-140-500), Difenoconazole $\geq 95 \%$, Carbenzadin $\geq 99.77 \%$, Oxytetracycline $\geq$ $95 \%$ and $\mathrm{NaCl} \geq 99 \%$ ), Tween ${ }^{\circledR} 80$ and tert-butanol anhydrous $\geq 99.5 \%$ were provided by Sigma-Aldrich Co (St. Louis, MO). Difenoconazole, Carbenzadin, Oxytetracycline and $\mathrm{NaCl}$ were used in this study to prepare the positive and negative control solutions.

\subsubsection{Preparation of methylimidazolium derivatives solutions and} suspension

The solutions were prepared in the following way, $60 \mathrm{mg}$ of the ionic liquids were solubilized with $3 \mathrm{~mL}$ of sterile water. The suspensions were obtained as follows, $60 \mathrm{mg}$ of the methylimidazolium derivatives were solubilized with $50 \mu \mathrm{l}$ of a solution with $1 \%$ of tert-butanol and Tween 80 , at $25^{\circ} \mathrm{C}$, using an emulsifier system with three key pathways coupled to a filter (cellulose ester $0.2 \mu \mathrm{m}$ ) with a pressure limit of $0.51 \mathrm{MPa}^{37}$. The final volume was adjusted to $3 \mathrm{~mL}$ with sterile water.

\subsubsection{Preparation of Nutrient Agar and Potato Dextrose Agar}

$28 \mathrm{~g}$ of Nutrient Agar or $39 \mathrm{~g}$ of PDA agar were suspended in one liter of distilled water. It was heated under constant stirring for one minute until the agar was completely dissolved. Subsequently, the medium was autoclaved at $121{ }^{\circ} \mathrm{C}$ and $15 \mathrm{lbs}$ pressure for 15 minutes to sterilize.

\subsubsection{Preparation of microbial suspensions}

To prepare the bacterial suspensions, cultures were grown for $24-48 \mathrm{~h}$ at $28^{\circ} \mathrm{C}$ in nutrient agar. Then, one or two colonies were picked from the agar surface, adjusted to turbidity of $0.5 \mathrm{McF}$ arland (corresponding to $1.5 \times 10^{8} \mathrm{UFC} / \mathrm{mL}$ ) and incubated at $28{ }^{\circ} \mathrm{C}$ for $2 \mathrm{~h}$ to allow the bacteria reach the exponential growth phase. Subsequently, using a sterile cotton swab the suspension was homogenously spread on the surface of nutrient agar. On the other hand, fungal were grown in solid medium PDA (Potato Dextrose Agar, Oxoid) incubated at $28{ }^{\circ} \mathrm{C}$ for 9 days. Then, spores were obtained from a fresh culture by scraping from the agar surface with a sterile spatula. Conidia were suspended in physiological solution plus $0,001 \%$. Tween $® 80$ and adjusted to a final concentration of $1 \times 10^{6}$ conidia/mL. The number of conidia was determined through direct microscopic in the Thoma-Zeiss counting chamber. The incubation time was prolonged up to $72 \mathrm{~h}$.

\subsection{Strains and isolates}

Antimicrobial activity was tested against 10 microorganisms. The experiment involved 6 strains of pathogenic bacteria (Escherichia coli ATCC 25922, Pseudomonas aeruginosa ATCC 27853, Staphylococcus ATCC 25923, Bacillus cereus ATCC 10876, Streptococcus mutans (Clinic isolates), Streptococcus agalactiae ATCC 12386) and 1 strain of non pathogenic bacteria (Bacillus subtilis subsp. spizizenii ATCC 6633). Additionally, two species of pathogenic fungi (Fusarium oxysporum,environmental isolates; Fusarium solani ATCC 34031) and one yeast species (Candida albicans ATCC 10231) were included in the study. Environmental isolate was provided by "Grupo Interdisciplinario de Estudios Moleculares-GIEM", Institute of Chemistry, University of Antioquia. Clinic isolate was supplied by the group "Investigación en Patología Oral, Periodoncia y Cirugía Alvéolo-Dentaria-POPCAD", Faculty of Dentistry, University of Antioquia. The other microorganisms were provided from a collection by the group "Investigación e Innovación en Formulaciones Químicas", Basic Sciences Department, University EIA.

\subsection{Antibacterial and antifungal activity}

The experiments were carried out by using the agar diffusion technique (also known as the Kirby-Bauer test ${ }^{38}$ described somewhat earlier by Abraham am coworkers in $1941^{39}$. The microorganisms were uniformly spread on the sterilized glass plates (by autoclaving) with Nutrient agar for bacteria and PDA for fungi and yeast, and wells of $5 \mathrm{~mm}$ (diameter) were punched under a sterilized condition (by heating with a Bunsen burner in a laminar flow chamber), with a sterile glass tube. Later, $5 \mathrm{~mm}$ filter paper discs (Schleicher and Schull, No. 595 ashes free) were impregnated with $20 \mu \mathrm{L}$ of each treatment (furanchalcone derivatives and ionic liquids) and they were placed into the wells ${ }^{40-41}$. The glass plates were then incubated at $37{ }^{\circ} \mathrm{C}$. The growth inhibition was measured after $24 \mathrm{~h}$ for bacteria and $72 \mathrm{~h}$ for fungi and yeast ${ }^{41}$. However, the fungi were monitored every $24 \mathrm{~h}$ for 9 days. Difenoconazole $(1.25 \mathrm{mg} / \mathrm{L})$ and Oxytetracycline $(2.5 \mathrm{mg} / \mathrm{L})$ were employed as positive antimicrobial controls for fungi and bacteria, respectively. The negative control was based in aqueous solutions of $\mathrm{NaCl} 0.9 \%(\mathrm{w} / \mathrm{v})$, tert-Butanol $1 \%(\mathrm{v} / \mathrm{v})$ and Tween ${ }^{\circledR} 800.001 \%$ $(w / v)$.

\subsection{Statistical Analysis}

Optimal concentrations were estimated by Probit Analysis ${ }^{42}$. Minimum concentrations to achieve 50\% inhibition $\left(\mathrm{MIC}_{50}\right)$ of the various bacteria and fungi, were considered significantly different if their $95 \%$ confidence limit did not overlap zero.

\subsection{In silico studies: Prediction of pharmacokinetic (PK) parameters}

The physicochemical parameters were determined using opensource cheminformatics toolkits such us Molinspiration software, ALOGPS 2.1 algorithm and Pre-ADMET 2.0 program to predicted various pharmacokinetic parameters and pharmaceutical relevant properties such as molecular weight (MW), total polar surface area (PSA), predicted aqueous solubility (Log S), apparent predicted intestinal permeability (App. Caco-2) prediction of binding to human serum albumin $\left(\log \mathrm{K}_{\mathrm{hsa}}\right.$ ), number of rotatable bonds, hydrogen bond acceptor site (n-OHNH) and hydrogen bong acceptors (n-ON). Polar surface area was used to calculated percentage human oral absorption (\% ABS) according to the equation $\% \mathrm{ABS}=109-[0.345 \times \mathrm{PSA}]^{43}$. These important parameters define absorption, permeability, movement and action of drug molecule.

\section{RESULTS AND DISCUSSION}

\subsection{Antimicrobial Activity}

The synthesis and characterization of the compounds under study (figure 2) has already been published ${ }^{44-47}$.

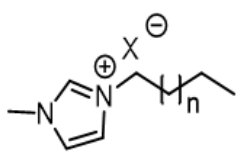

1. $n=1, X=B r$

2. $n=1, X=B F_{4}$

3. $\mathrm{n}=5, \mathrm{X}=\mathrm{Br}$

4. $n=5, X=B F_{4}$

5. $n=13, X=B r$

6. $n=13, X=O H$

7. $n=13, X=B F_{4}$

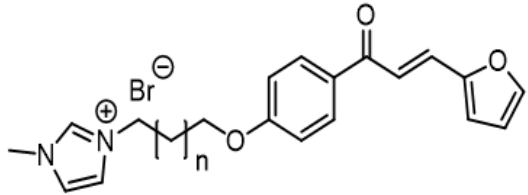

8. $n=1$

9. $\mathrm{n}=2$

10. $n=3$

11. $n=6$

12. $n=7$

13. $n=10$
Figure 2. Chemical structures of 3-methylimidazolium salts and 3methylimidazolium-furanchalcone hybrids.

Many infectious pathogens have developed resistance to conventional drugs. Considering the current prevalence of resistant pathogens, there is an urgent need to discover and develop novel classes of potent compounds which could either replace traditional drugs or be used in combinatorial approaches to combat this increase in antimicrobial resistance ${ }^{48}$. Thus, the antimicrobial activity of 3 methylimidazolium salts (ionic liquid, 1-7) and 3-methylimidazoliumfuranchalcone hybrids (8-13), was evaluated, together with the reference drugs (oxytetracycline and difenoconazole) and the lead compounds (furanchalcone, methylimidazole or the mixture of them). The activity was expressed as $\mathrm{MIC}_{50}$ (minimum inhibitory concentration, see table 1) and percentage of inhibition values (see figure 3 ) of the compounds with regard to controls. As shown in Figure 3, compounds 3-5 displayed activity against the gram negative bacteria $E$. coli, being compound 3 the one which displayed the highest activity, with values that are comparable to the reference drug, oxytetracycline. On the other hand, when all compounds were evaluated against gram positive bacteria, there was a broader spectrum of activity. Hybrid 11 exhibited the highest activity against $S$. aureus (inhibition $=81 \%$ ) and compounds 3, 4 and 7 displayed the greatest 
activity against the Streptococcus genus, being compounds 3 and 4 the most active against $S$. mutans, an important dental pathogen which is also associated with bacteremia and infective endocarditis ${ }^{49}$, and compound 7 the most active against the opportunistic human pathogen $S$. agalactiae. In addition, none of the compounds evaluated displayed activity against the gram negative $P$. aeruginosa, besides, compounds 1 and 8 did not exhibit any activity against the microorganisms evaluated.
When these compounds were analyzed against human fungal pathogens, it was noticed that ionic luquid $\mathbf{3}$ was the most active, displaying 100\% of inhibition against $F$. solani, followed by compounds $\mathbf{1 0}$ and $\mathbf{1 1}$ with activities higher than $70 \%$. These results are comparable with those for the reference drug, difenoconazole. Furthermore, hybrids $\mathbf{7}$ and $\mathbf{1 0}$ exhibited the highest inhibition against the yeast $C$. albicans and $F$. oxysporum, respectively $(7: 87 \% ; 10: 71 \%)$ (Figure 3).
A

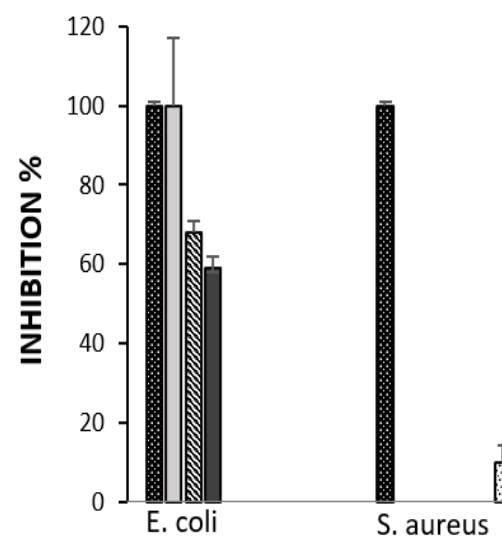

B

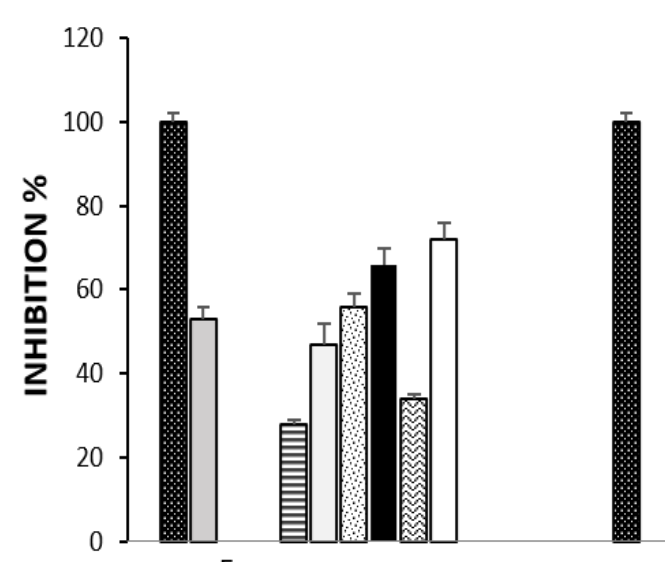

F. oxysporum

\section{ANTIFUNGAL ACTIVITY}

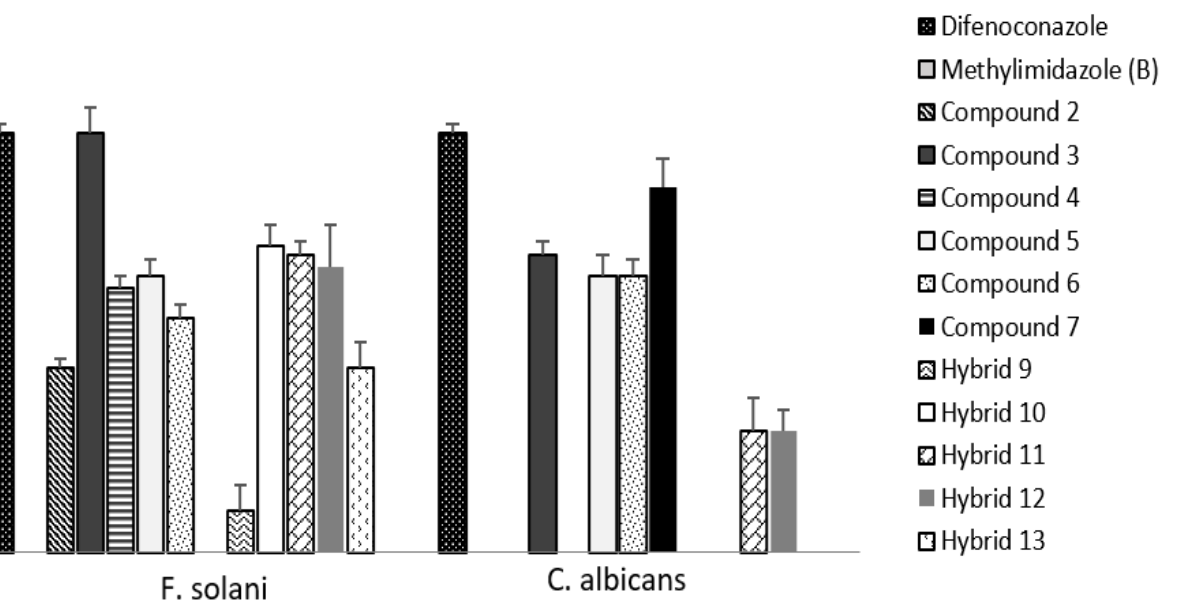

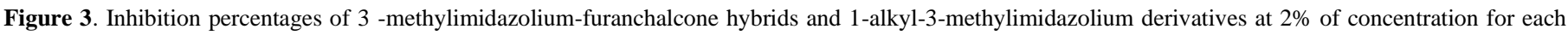

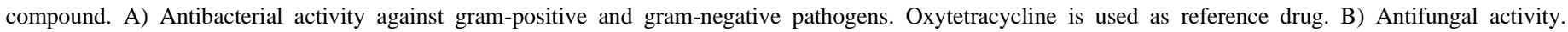

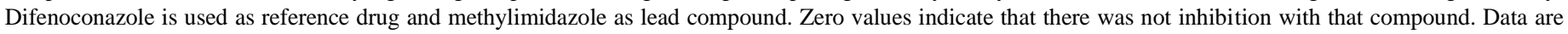
presented as the mean \pm Standard Error (SE) of three independent experiments.

Although the results showed that antifungal and antibacterial activities against all the evaluated strains are lower in comparison to the standard drugs oxytetracycline and difenoconazole ( $\mathrm{MIC}_{50}$ values ranging from 3.0-181.3 mM), it is interesting to note that most of the compounds were more active than the lead compounds alone (Table 1), showing that chemical derivatization and hybridization enhance biological properties, that, in the case of hybrids, could probably be attibuted to the synergistic effect, highlighting the importances of further investigations on this matter.

On a SAR basis, it was observed that, when the alkyl linker was eigth carbon atoms, compounds displayed the highest bioactivity. However, although imidazolium salts with longer alkyl chain had a greater spectrum of activity, it was not possible to stablish a clear relationship between the antimicrobial activity and the length of the alkyl linker, since the same compounds with short alkyl chains or the hybrids with short and long alkyl chains did not exhibit good biological activity. These results were not consistent with another report, in which the introduction of a longer substituent on the imidazolium cation resulted in high biostatic activities ${ }^{24}$. On the other hand, no significant changes in antimicrobial activity were observed when the anion was changed. These results indicate a weak dependence between the antimicrobial activity and counterion (compounds 3 vs 4, 5-7) ${ }^{24}$.

One possible mechanism of action for these compounds may be formulated in terms of an insertion into the lipid bilayer causing changes in the structural and dynamic properties of this, which could be the cause of its disruption ${ }^{50}$. All these findings and the differences in the activity in fungus and gram-negative or grampositive bacteria, show the great importance of the membrane in the microbial inhibition together with the structure of the compounds ${ }^{51}$. 
Table 1. Antibacterial and antifungal activity of 3-methylimidazolium-furanchalcone hybrids and 1-alkyl-3-methylimidazolium derivatives.

\begin{tabular}{|c|c|c|c|c|c|c|c|c|c|c|}
\hline \multirow{3}{*}{ Compound } & \multicolumn{10}{|c|}{$\mathrm{MIC}_{50}(\mathrm{mM}) \pm \mathrm{SE}$} \\
\hline & \multicolumn{2}{|c|}{ Gram-negative bacteria } & \multicolumn{5}{|c|}{ Gram-positive bacteria } & \multicolumn{3}{|c|}{ Fungi } \\
\hline & E. coli & P. aeruginosa & S. aureus & S. agalactiae & S. mutans & B.cereus & B. spizizenii & F. oxysporum & F. solani & C.albicans \\
\hline 1 & - & - & - & - & - & - & - & - & - & \\
\hline 2 & - & - & - & - & - & - & - & - & $99.3 \pm 5$ & \\
\hline 3 & $10.7 \pm 0.4$ & - & - & $55.2 \pm 2$ & $19.5 \pm 1$ & - & $123.4 \pm 6$ & - & $16.4 \pm 0.5$ & $45.3 \pm 2$ \\
\hline 4 & $15.7 \pm 0.6$ & - & - & - & $3.0 \pm 0.2$ & - & - & $13.5 \pm 0.7$ & $10.3 \pm 0.5$ & \\
\hline 5 & $36.7 \pm 2$ & - & - & $33.1 \pm 0.7$ & $14.9 \pm 0.8$ & $37.9 \pm 2$ & $32.8 \pm 1$ & $9.0 \pm 0.5$ & $29.9 \pm 1$ & $8.5 \pm 0.4$ \\
\hline 6 & - & - & - & $111.5 \pm 5$ & $16.0 \pm 0.5$ & $41.7 \pm 2$ & $39.5 \pm 2$ & $10.5 \pm 0.4$ & $46.7 \pm 1$ & $11.5 \pm 0.5$ \\
\hline 7 & - & - & - & $23.6 \pm 0.7$ & - & $44.1 \pm 1$ & $23.6 \pm 0.9$ & $6.7 \pm 0.3$ & - & $9.2 \pm 0.7$ \\
\hline 8 & - & - & - & - & - & - & - & - & - & \\
\hline 9 & - & - & - & - & - & - & - & $26.0 \pm 1$ & $68.2 \pm 2$ & \\
\hline 10 & - & - & $181.3 \pm 9$ & - & - & - & - & $21.0 \pm 0.6$ & $14.3 \pm 0.7$ & \\
\hline 11 & - & - & $14.6 \pm 0.5$ & $80.4 \pm 4$ & $18.7 \pm 0.7$ & $40.7 \pm 1$ & $57.2 \pm 3$ & - & $14.5 \pm 0.8$ & $46.8 \pm 2$ \\
\hline 12 & - & - & $30.8 \pm 1$ & $110.5 \pm 3$ & $25.8 \pm 2$ & - & - & - & $19.7 \pm 1$ & $189.9 \pm 9$ \\
\hline 13 & - & - & $29.6 \pm 2$ & - & - & - & - & - & $22.9 \pm 0.7$ & \\
\hline Furanchalcone (A) & - & - & - & - & - & - & - & - & - & \\
\hline $\begin{array}{l}\text { Methylimidazole } \\
\text { (B) }\end{array}$ & - & - & - & - & - & - & - & $315.0 \pm 22$ & - & \\
\hline Mixture $(A+B)$ & - & - & - & - & - & - & - & - & - & - \\
\hline Oxytetracycline & $0.014 \pm 0.0007$ & $0.014 \pm 0.0007$ & $0.014 \pm 0.0007$ & $0.014 \pm 0.0007$ & $0.014 \pm 0.0007$ & $0.014 \pm 0.0007$ & $0.014 \pm 0.0007$ & NA & NA & NA \\
\hline Difenoconazole & $\mathrm{NA}$ & $\mathrm{NA}$ & $\mathrm{NA}$ & $\mathrm{NA}$ & $\mathrm{NA}$ & $\mathrm{NA}$ & $\mathrm{NA}$ & $0.008 \pm 0.002$ & $0.008 \pm 0.002$ & $0.008 \pm 0.002$ \\
\hline
\end{tabular}

Data are presented as the mean \pm Standard Error (SE) of three independent experiments. NA: Not Applicable.

\subsection{In Silico ADMET Investigation Results}

In silico drug-likeness prediction along with further ADMET tools present an array of opportunities which help to accelerate the discovery of new drugs. We carried out an in silico ADMET study for the 3-methylimidazoliumfuranchalcone hybrids and 1-alkyl-3-methylimidazolium derivatives and analyzed various drug-likeness properties. As shown in Table 2, molecules 1$\mathbf{1 3}$ showed significant values for the parameters analyzed, exhibiting good drug like characteristics, besides, the values were found within the range of properties of $95 \%$ of currently known drugs. Moreover, according to Lipinski's rule of five 52 (an orally active drug has no more than one violation of the criteria) the compounds tested could be orally active drugs in human. In addition, all the title compounds exhibited good percent absorption (\% ABS) ranging from 88.9 to $105 \%$ which indicates that these compounds are non-toxic in nature. These results of this in silico ADMET prediction analysis suggest that the novel compounds 1-13 represent a pharmacologically active framework that should be considered on progressing further potential hits.

There are some useful strategies to predict interactions between drugs and biological models. In this matter, applicability of physicochemical properties provides modelling approaches such as structure-activity relationship (SAR) for many processes including passive membrane permeation, where the molecular mechanism is hardly delineated. On the other hand, there is a descriptor called Polar Surface Area (PSA) that allows to predict drug-membrane interactions and correlates well with passive molecular transport through membranes. According with the results obtained, the comparison of calculated PSA ${ }^{53}$ values for compounds 1-7 $\left(8.82 \AA^{2}\right)$ with regard to hybrids 8-13 $\left(48.26 \AA^{2}\right)$, displayed a large deviation. Thus, when PSA was applied, a correlation between PSA values and $\mathrm{MIC}_{50}$ values showed that high values of PSA (hybrids 8-13) contributed to a reduction of their spectrum antimicrobial activity, whereas low PSA values like in compounds 1-7, promoted this spectrum. This findings probably suggest that these lipophilic compounds have a greater affinity and good ability to penetrate the lipid bilayer of the bacterial and fungal cell wall. In addition, due to the differences in the fatty acid composition between gram-negative, gram-positive bacteria and fungus, the hydrophobic terminal moiety in the compounds 1-7 could be essential for initial binding and perturbation of the lipid bilayer in the microbial membrane surface, leading to permeabilization and eventually membrane disruption, which shows a correlation between the calculated value (PSA) and bacterial or fungal cell wall permeability. On the other hand, hybridization of the compounds with the nucleus of chalcone (hybrids 8-13) showed a low spectrum of antimicrobial activity, which could be due to the fact that this new nucleus avoided an effective approach of the molecule to the cell wall.

Another useful parameter to determine the interaction between a compound and the cell wall is the $\log \mathrm{P}$ value, which gives a measure of the lipophilicity, an important property of a drug molecule that influences a number of physiological properties including transport through lipid bilayer. This parameter is a good indicator of permeability across the cell wall. According with the results obtained, $\log \mathrm{P}$ values of compounds with short-alkyl chain on $\mathrm{N}$ (including methylimidazole) as in compounds $\mathbf{1 - 3}$ or hybrids 8-10 with negative values for $\log \mathrm{P}(-0.30$ to -0.57 , meaning low liposolubility) showed poor or absent results for antimicrobial activity. On the other hand, when long-chains on $\mathrm{N}$ were present in the molecules, these displayed a broad-spectrum activity, since compounds structurally mimic fatty acids in the microbial cell wall, allowing an efficient interaction between them.

Additionally, we calculated the number of rotatable bonds (Nrot), a simple topological parameter to measure molecular flexibility that can be used to discard structures with not drug-like properties and to pick potential drug candidates. According to this, we correlated the contribution of molecular rigidity with regard to anti-microbial activity and the number of rotatable bonds for the tested compounds 1-13 (see Table 2). We found that compounds containing Nrot bond higher than 13 exhibited a broad-spectrum antimicrobial (compounds 4-7 and hybrids 10-13). This conformational flexibility facilitates hydrophobic interactions that could increase the absorption or permeation for disrupting cell wall in bacteria or fungus. Besides, in biological systems these hydrophobic interactions are the strongest long-range noncovalent interactions and they are critical for microbial-surface interactions ${ }^{54}$. 
Table 2. In silico physicochemical pharmacokinetic parameters of compounds 1-1.

\begin{tabular}{|c|c|c|c|c|c|c|c|c|c|c|c|c|}
\hline Entry & M.W a & $\begin{array}{c}\mathbf{P S A}^{\mathbf{b}} \\
\left(7-200 \AA^{2}\right)\end{array}$ & $\begin{array}{c}\text { n-Rot } \\
\text { Bond }\end{array}$ & $\begin{array}{c}\text { n-ON } \\
(<10)\end{array}$ & $\underset{(<5)}{\mathrm{n}-\mathrm{OHNH}^{\mathrm{e}}}$ & $\mid \begin{array}{c}\log P o / w \\
(-2.0-6.5)\end{array}$ & $\begin{array}{c}\log S^{g} \\
(-6-0.5)\end{array}$ & $\begin{array}{l}\text { Log Khsa }^{h} \\
(-1.5-1.2)\end{array}$ & App. Сaco-2 ${ }^{\mathrm{i}}$ & $\% \mathbf{A B S}^{\mathbf{j}}$ & $\begin{array}{c}\text { Lipinski Rule } \\
\text { of five }(\leq 1)\end{array}$ & $\%$ HOA $^{k}$ \\
\hline 1 & 226.02 & 8.82 & 3 & 0 & 2 & -2.04 & -3.310 & 2.0 & 21.122 & 105.96 & 0 & 100 \\
\hline 2 & 219.12 & 8.82 & 3 & 0 & 2 & -2.04 & 1.909 & 0.99 & 21.069 & 105.96 & 0 & 100 \\
\hline 3 & 275.23 & 8.82 & 7 & 0 & 2 & -0.02 & 0.359 & 1.86 & 21.093 & 105.96 & 0 & 100 \\
\hline 4 & 282.13 & 8.82 & 7 & 0 & 2 & -0.02 & -4.861 & 2.0 & 21.178 & 105.96 & 0 & 100 \\
\hline 5 & 387.44 & 8.82 & 15 & 0 & 2 & 4.02 & -2.741 & 2.0 & 21.109 & 105.96 & 0 & 100 \\
\hline 6 & 324.54 & 8.82 & 15 & 0 & 2 & 4.02 & -4.568 & 1.98 & 23.713 & 105.96 & 0 & 100 \\
\hline 7 & 394.34 & 8.82 & 15 & 0 & 2 & 4.02 & -7.962 & 2.0 & 21.281 & 105.96 & 1 & 100 \\
\hline 8 & 417,30 & 48.26 & 8 & 0 & 5 & -0.57 & -1.269 & 1.55 & 21,0913 & 92.35 & 0 & 97 \\
\hline 9 & 431,32 & 48.26 & 9 & 0 & 5 & -0.30 & -1.407 & 1.57 & 21,0926 & 92.35 & 0 & 97 \\
\hline 10 & 445,35 & 48.26 & 10 & 0 & 5 & 0.20 & -1.794 & 1.72 & 21,0941 & 92.35 & 0 & 97 \\
\hline 11 & 487,43 & 48.26 & 13 & 0 & 5 & 1.72 & -2.957 & 1.91 & 21,0990 & 92.35 & 0 & 98 \\
\hline 12 & 501,46 & 48.26 & 14 & 0 & 5 & 2.22 & -3.345 & 1.94 & 21,1007 & 92.35 & 1 & 98 \\
\hline 13 & 543,54 & 48.26 & 17 & 0 & 5 & 3.74 & -4.508 & 1.99 & 21,1064 & 92.35 & 1 & 98 \\
\hline Furanchalcone & 214.220 & 58.26 & 5 & 1 & 3.25 & 2.225 & -2.585 & -0.202 & 1126 & 88.90 & 0 & 95 \\
\hline Methylimidazole & 82.105 & 16.70 & 0 & 0 & 2 & 0.514 & -0.352 & -0.814 & 4785 & 103.23 & 0 & 96 \\
\hline
\end{tabular}

${ }^{\mathrm{a}}$ Molecular weight of the molecule; ${ }^{\mathrm{b}}$ flexible rotatable bond count (n-rot) ; ${ }^{\mathrm{C}}$ Polar surface area (PSA) (7.0-200.0); ${ }^{\mathrm{d}} \mathrm{n}$-ON number of hydrogen bond acceptors _ $10 ;{ }^{\mathrm{e}} \mathrm{n}$-OHNH number of hydrogen bonds donors $\leq 5 ;{ }^{\mathrm{f}}$ Predicted octanol-water partition coefficient ( $\log \mathrm{P}$ o/w) $(-2.0$ to 6.5$)$; ${ }^{\mathrm{g}}$ Logarithm of Aqueous solubility (Log S) (-6 to 0.5); ${ }^{\mathrm{h}}$ Logarithm of predicted binding constant to human serum albumin (log Khsa) (-1.5 to 1.2); ${ }^{\mathrm{i}}$ Predicted intestinal permeability model (App. Caco$2) ;{ }^{j}$ Percentage human oral absorption (\% ABS) $\left(>80 \%\right.$ is high, $<25 \%$ is poor); ${ }^{k}$ per cent of human oral absorption (HOA \%).

\section{CONCLUSION}

A set of methylimidazolium-furanchalcone hybrids and 1-alkyl-3methylimidazolium salts (ionic luquid) were tested in order to find their antibacterial and antifungal activities. Among the tested compounds, derivatives 4 and 7 were the most active against $S$. mutans and $F$. On the other hand, among the hybrid molecules, compound 11 displayed the best activity against $S$. aureus and $S$. mutans, besides, together with compound 10 , exhibited the best antifungal activity against and $F$. solani. In the structure-activity relationship there was not significant changes in biological activity when the anion was changed, however, we observed higher bioactivity when the alkyl linker had eigth carbon atoms.

Furthermore, the in silico results displayed a strong relationship between the length of the alkyl chain on $\mathrm{N}$ with their antimicrobial activity. Although the results displayed lower antifungal and antibacterial activities in comparison to the standard drugs it is interesting to highlight that most of them were more active than the lead compounds alone, which suggests that further studies in this field are needed to find new molecules that enhance biological activity and help to reduce the current prevalence of resistant pathogens.

\section{ACKNOWLEDGEMENT}

This study was supported by the University of Antioquia, University EIA and Corporación Universitaria Americana.

\section{CONFLICT OF INTEREST}

No conflict of interest associated with this work.

\section{REFERENCES}

1. As antibiotic discovery stagnates, IDSA; 2004.

2. S.J. Howard, M. Catchpole, J. Watson, S.C. Davies, Lancet Infect. Dis., 13, 1001, (2013).

3. R. Laxminarayan, A. Duse, C. Wattal, A.K. Zaidi, H.F. Wertheim, N. Sumpradit, E. Vlieghe, G.L.Hara, I.M. Gould, H. Goossens, C. Greko, A.D. So, M. Bigdeli, G. Tomson, W. Woodhouse, E. Ombaka, A.Q. Peralta, F.N. Qamar, F. Mir, S. Kariuki, Z.A. Bhutta, A. Coates, R. Bergstrom, G.D.Wright, E.D. Brown, O. Cars, Lancet Infect. Dis. 3, 1057, (2013).

4. H.W. Boucher, G.H. Talbot, J.S. Bradley, J.E. Edwards, D. Gilberto, L.B. Rice, M. Scheld, B. Spellberg, J. Bartlett, Clin. Infect. Dis. 48, 1, (2009).
5. R.D. Cannon, E. Lamping, A.R. Holmes, K. Niimi, P.V. Baret, M.V. Keniya, K. Tanabe, M. Niimi, A. Goffeau, B.C. Monk, Clin. Microbiol. Rev. 22, 291, (2009).

6. P.G. Pappas, C.A. Kauffman, D. Andes, D.K. Benjamin Jr, T.F. Calandra, J.E. Edwards Jr, S.G. Filler, J.F. Fisher, B.J. Kullberg, L.O. Zeichner, C. Reboli, J.H. Rex, T.J. Walsh, J.D. Sobe. Clin. Infect. Dis. 48, 503 (2009).

7. J.M. Achkar, B.C. Fries. Clin. Microbiol. Rev. 23, 253 (2010).

8. M.K. Kathiravana, A.B. Salake, A.S. Chothe, P.B. Dudhea, R.P. Watodea, M.S. Muktaa, S. Gadhwea. Bioorg. Med. Chem. 20, 5678 (2012).

9. L. De Luca. Curr Med Chem 13, 1 (2006).

10. L. Zhang, X.M. Peng, G.L.V. Damu, R.X. Geng, C.H. Zhou. Med. Res. Rev. 34, 340 (2014)

11. D. Zampieri, M.G. Mamolo, L. Vio, E. Banfi, G. Scialino, M. Fermeglia, M. Ferrone, S. Pricl. Bioorg. Med. Chem. 15, 7444 (2007).

12. J. Gising, M.T. Nilsson, L.R. Odell, S. Yahiaoui, M. Lindh, H. Iyer, A.M Sinha, B.R. Srinivasa, M. Larhed, S.L. Mowbray, A.J. Karlén. Med. Chem. 55, 2894 (2012).

13. A. Puratchikodya, M. Doble, Bioorg. Med. Chem. 15, 1083 (2007).

14. R. Selig, M. Goettert, V. Schattel, D. Schollmeyer, W. Albrecht, S. Laufer, J. Med. Chem. 55, 8429 (2012).

15. J. Pandey, V.K. Tiwari, S.S. Varma, V. Chaturvedi, S. Bhatnagar, S. Sinha, A.N. Gaikwad, R.P. Tripathi. Eur. J. Med. Chem. 44, 3350 (2009).

16. G. La Regina, F.D. D’Auria, A. Tafi, F. Piscitelli, S. Olla, F. Caporuscio, L. Nencioni, R. Cirilli, F. La Torre, N.R. De Melo, S.L. Kelly, D.C. Lamb, M. Artico, M. Botta, A.T. Palamara, R. Silvestri, J. Med. Chem. 51, 3841 (2008).

17. R.A. Al-Qawasmeh, M. Huesca, V. Nedunuri, R. Peralta, J. Wright, Y. Lee, Y. Young, Bioorg. Med. Chem. Lett. 20, 3518 (2010).

18. A. Cornellas, L. Perez, F. Comelles, I. Ribosa, A. Manresa, M.T. Garcia, J. Colloid Interface Sci. 355, 164 (2011).

19. P. Borowiecki, M. Milner-Krawczyk, D. Brzezinska, M. Wielechowska, J. Plenkiewicz, Eur. J. Org. Chem. 4, 712 (2013).

20. P. Mester, M. Wagner, P. Rossmanith. Ecotoxicol. Environ. Saf. 111, 96 (2015).

21. J. Yu, S. Zhang, Y. Dai, X. Lu, Q. Lei, W. Fang, J. Hazard Mater 307, 73 (2016).

22. J. Pernak, K. Sobaszkiewicz, I. Mirska, Green Chem. 5, 52 (2003).

23. D. Demberelnyamba, K.S. Kim, S.J. Choi, S.Y. Park, H. Lee, C.J. Kim, I.D. Yoo, Bioorg. Med. Chem. 12, 853 (2004).

24. A. Romero, A. Santos, J. Tojo, A. Rodriguez, J, Hazard Mater., J. Hazard Mater. 151, 268 (2008).

25. M.T. Garcia, N. Gathergood, P.J. Scammells, Green Chem. 7, 9 (2005). 
26. J. Luczak, C. Jungnickel, I. Lacka, S. Stolte, J. Hupka. Green Chem. 12, 593 (2010).

27. a) A. Budhiraja, K. Kadian, M. Kaur, V. Aggarwal, A. Garg, S. Sapra, K. Nepali, O.P. Suri, K.L. Dhar, Med. Chem. Res. 21, 2133 (2012) b) S Kantevari, D. Addla, P.K. Bagul, B. Sridhar, S.K. Banerjee. Bioorg. Med. Chem. 19, 4772 (2011) c) S.U.F. Rizvi, H.L. Siddiqui, M. Johns, M. Detorio, R.F. Schinazi, Med. Chem. Res. 21, 3741 (2012) d) D.A. Israf, T.A. Khaizurin A. Syahida, N.H. Lajis, S. Khozirah. Mol. Immunol. 44, 673 (2007) e) N. Aoki, M. Muko, E. Ohta, S. Ohta. J. Nat. Prod. 71, 1308 (2008) f) V. Tomar, G. Bhattacharjee, Kamaluddin, S. Rajakumar, K. Srivastava, S.K. Puri, Eur. J. Med. Chem. 45, 745 (2010) g) M. Chen, S.B. Christensen, J. Blom, E. Lemmich, L. Nadelmann, K. Fich, T.G. Theander, A. Kharazmi. Antimicrob. Agents Chemother. 37, 2550 (1993) h) M.I. Abdullah, A Mahmood, M. Madni, S. Masood, M. Kashif, Bioorg. Chem. 54, 31 (2014) g) K.V. Lahtchev, D.I. Batovska, S.P. Parushev, V.M. Ubiyvovk, A.A. Sibirny, Eur. J. Med. Chem. 43, 2220 (2008).

28. M.A.Munawar, M. Azad, H.L. Siddiqui, J. Chin. Soc. 55, 394 (2008)

29. M. Azad, M.A. Munawar, H.L. Siddiqui, J. Appl. Sci. 7, 2485 (2007).

30. R. Kalirazan,; S.U. Sivakumar, S. Julie, B. Gowramma, B. Suresh, Int. J. Chemtech. Res. 1, 27 (2009).

31. S.N. Lopez, V. Marıa Castelli, S.A. Zacchino. Bioorg. Med. Chem. 9, 1999 (2001).

32. C.T. Keith, A. Borisy, B.R. Stockwell. Nat. Rev. Drug Discov. 4, 71 (2005)

33. B. Meunier, Acc. Chem. Res. 41, 69 (2008).

34. I. Opsenica, D. Opsenica, C.A. Lanteri, L. Anova, W.K. Milhous, K.S. Smith, B.A. Solaja, J. Med.Chem. 51, 6216 (2008)

35. B.L. Roth, D.J. Sheffler, W.K. Kroeze, Nat. Rev. Drug Discov. 3, 353 (2004).

36. J.J. Walsh, D. Coughlan, N. Heneghan, C. Gaynor, A. Bell, Bioorg. Med. Chem. Lett. 17, 3599. (2007).

37. P. Araque, C. Peláez, Revista Vitae 17, 83 (2010).

38. A.W. Bauer, W.M.M. Kirby, J.C. Sherris, M. Turck. Am. J. Clin. Pathol 45, 493 (1966).
39. E.P. Abraham, A.D. Gardner, E.B. Chain, N.G. Heatley, C.M. Fletcher, M.A. Jennings, H.W. Florey, Lancet ii, 177 (1941).

40. I. Hossain, M.E. Harbawi, Y.A. Noaman, M.A.B. Bustam, N.B.M. Alitheen, N.A. Affandi, G. Hefter, C.Y. Yin. Chemosphere 84, 101 (2011).

41. K. Silva, S. Rodrigues, L. Filho, A. Lima, Appl. Biochem. Biotechnol. 152, 316 (2009).

42. Finney, D. J., 3rd Ed. (1971). Probit Analysis. Cambridge, England, Cambridge University Press.

43. Y. Zhao, M.H. Abraham, J. Lee, A. Hersey, N.C. Luscombe, G. Beck, B. Sherborne, I. Cooper, Pharm. Res. 19, 1446 (2002).

44. B.C. Ranu, S. Banerjee, Org. Lett. 7, 3049 (2005)

45. S.L. Fulmer, D.P. Richardson, T.E. Smith, S. Wolff, Org. Synth. 79, 236 (2002).

46. D.F. Montaño, H. Casanova, W.I. Cardona, L.F. Giraldo, Mater. Chem. Phys. 198, 386 (2017).

47. E. García, J.C. Coa, E. Otero, M. Carda, I.D. Vélez, S.M. Robledo, W.I. Cardona. Med. Chem. Res. 27, 497 (2018).

48. C.D. Sumi, B.W. Yang, I.C. Yeo, Y.T. Hahm, Can. J. Microbiol. 61, 93 (2015).

49. N. Kazuhiko, N. Ryota, O. Takashi, Jpn Dent Sci Rev 44, 29 (2008)

50. B. Yoo, B. Jing, S.E. Jones, G.A. Lamberti, Y. Zhu, J.K. Shan, E.J. Maginn, Sci. Rep. 6, 19889 (2016).

51. B.J. Denny, L. Novotny, P.W.J. West, M. Blesova, J. Zamocka, Med. Princ. Pract. 14, 377 (2005).

52. C.A. Lipinski, F. Lombardo, B.W. Dominy, P.J. Feeney, Adv. Drug Deliv. Rev. 23, 3 (1997).

53. P. Ertl, B. Rohde, P. Selzer. J. Med.Chem. 43, 3714 (2000).

54. a) N. Yang, M. Hinner, Methods Mol. Biol. 1266, 29 (2015) b) J.T. Gannon, V.B. Manilal, M. Alexander, Appl. Environ. Microbiol. 57, 190 (1991) c) K.M, Małgorzata, Z. Andrzej, R.G. Anna, L. Katarzyna, S. Leon, Microbiology 147, 2769 (2001) d) D.F. Veber, S.R. Johnson, H.Y. Cheng, B.R. Smith, K.W. Ward, K.D. Kopple. J. Med. Chem. 45, 2615 (2002). 